Postprint version. Original publication in:

Ecological Entomology (2009) 34(6): 709-717

doi: 10.1111/j.1365-2311.2009.01121.x

\title{
Responses of generalist invertebrate predators to pupal densities of autumnal and winter moths under field conditions
}

\author{
Annette Heisswolf, Netta Klemola, Tea Ammunét, Tero Klemola \\ Department of Biology, University of Turku, FI-20014 Turku, Finland
}

\begin{abstract}
Generalist natural enemies are usually not considered as being capable of causing population cycles in forest insects, but they may influence the population dynamics of their prey in the low density cycle phase when specialist enemies are largely absent.

2. In the present field study, the total response of the generalist invertebrate predator community to experimentally established pupal densities of the closely related autumnal (Epirrita autumnata) and winter moths (Operophtera brumata) was analysed.

3. Due to the high amount of variation in the dataset, the exact shape of the response curve could not be convincingly estimated. Nevertheless, two important conclusions can be drawn from the analyses.

4. Firstly, the natural invertebrate predator community seems to become saturated at rather low densities of both autumnal and winter moth pupae. Secondly, the predator community seems to become saturated at much lower densities of autumnal than of winter moth pupae.

5. Furthermore, pupal mass was significantly negatively correlated with invertebrate predation probability in autumnal moth pupae.

6. These results indicate that differences in the predator assemblage being able to consume pupae of the two moth species, as well as different handling times, could be responsible for the substantially higher predation rates in winter than in autumnal moth pupae.

7. As a consequence, the population dynamics of autumnal moths might be less affected by generalist invertebrate predators than those of winter moths, as autumnal moths seem able to escape from the regulating influence of generalist predators at much lower population densities than winter moths.
\end{abstract}

Key words. Density-dependent predation, Epirrita autumnata, forest Lepidoptera, Operophtera brumata, population dynamics, pupal predation.

\section{INTRODUCTION}

Cyclic population dynamics of outbreaking forest pests have fascinated researchers ever since they were first observed. As a consequence, numerous studies have been 
conducted to reveal the factors driving population cycles (Berryman, 1988, 1996; Myers, 1988). In forest-defoliating Lepidoptera, the most often suggested factors causing cyclicity are delayed density-dependent interactions with host plants (via quality/defence) and natural enemies, particularly specialised parasitoids/pathogens (Anderson \& May, 1980; Berryman, 1987; Haukioja et al., 1988; Myers, 1988; Berryman, 1996; Ruohomäki et al., 2000; Tanhuanpää et al., 2002).

Generalist natural enemies are usually not considered as being capable of causing high-amplitude population cycles in forest insects, as they rarely interact with their prey in a delayed density-dependent fashion (Turchin, 2003). Nevertheless, they may contribute to the characteristics of cycles caused by other mechanisms, especially in low-density phases of the cycle when specialised enemies are largely absent (see examples in Berryman, 1987). Direct density-dependent predation by generalists, for example, may have a stabilising influence on cyclic prey population dynamics (Hanski et al., 1991). However, once the population density of a pest species surpasses the saturation point of its generalist predators, the pest species escapes from their influence. Other regulating factors, such as specialist predators, then come into play (Holling, 1965; Berryman, 1987). This saturation point depends both on the prey species and the predators. Therefore, in order to comprehensively reveal the influence of generalist predators on population cycles in nature, their responses to prey density need to be studied.

Predators can respond in various ways to changes in prey density. Most commonly, four response types are distinguished: (1) numerical, (2) aggregative, (3) functional, and (4) developmental responses (Holling, 1959). A numerical response of predators can occur as a result of reproduction by the predator. An aggregative response results from the movements or concentrations of predators in areas of high prey density. The functional response measures how many prey items each individual predator eats per given time period, while the developmental response describes changes in predator feeding due to growth and maturation. The combination of all these responses results in the total response of the predator to prey density, which is measured as the per cent of prey organisms eaten per unit time by the entire predator population.

In order to elucidate the various kinds and shapes of predator responses to prey density in a given system, detailed information about predators and prey, e.g. population densities, age structure, individual foraging behaviour, is necessary. As a consequence, the majority of empirical studies on predator-prey models have been conducted under laboratory conditions (e.g. Desurmont \& Weston, 2008; Mahdian et al., 2008; Seko \& Miura, 2008), where many aspects of the predator-prey interaction can be controlled. However, the results of such studies have often proved difficult to translate to field populations (Sih et al., 1998; Lester \& Harmsen, 2002) due, among other factors, 
to the unavoidable simplifications of laboratory experiments. Furthermore, depending on the predator-prey system, even laboratory set-ups may not suffice in providing all the necessary information, for example if both predators and prey are soil-dwelling species and predation events cannot be observed directly. Field experiments, on the other hand, at least provide valuable information about the total response of the natural predator community to prey density, which can be used to estimate the importance of predation on population dynamics. Thus, there is an obvious trade-off between laboratory and field experiments concerning the amount of detailed information that can be gained and the relevance of the results for natural populations.

The focus of this study is on the autumnal moth, Epirrita autumnata (Borkhausen), and the winter moth, Operophtera brumata (Linnaeus), which are two closely related species of geometrid moths (Lepidoptera: Geometridae). Both are serious pests on the mountain birch, Betula pubescens ssp. czerepanovii (Orlova) Hämet-Ahti (Fagales: Betulaceae), in the Scandinavian mountains and northern Fennoscandia (Tenow, 1972; Haukioja et al., 1988). There, both moth species have cyclic population dynamics and reach their peak with or without outbreak densities every 9-10 years (Tenow, 1972; Haukioja et al., 1988; Klemola et al., 2006). Previously, the species have been showing synchronous peak densities and outbreaks or the winter moth has lagged 1-3 years behind the autumnal moth (Tenow, 1972; Tenow et al., 2007; Klemola et al., 2008).

The population dynamics of autumnal and winter moths have been extensively studied over a long period of time in Fennoscandia (Ims et al., 2004; Klemola et al., 2006; Tenow et al., 2007; Jepsen et al., 2008). However, the contribution of generalist predators to population dynamics has mainly been examined with relation to explaining differences between outbreaking and non-outbreaking populations (Tanhuanpää et al., 1999, 2003; Klemola et al., 2002; Raymond et al., 2002). So far, pupal predation by generalists seems to be the only factor having the potential of regulating autumnal moth populations without high-amplitude cycles in southern Finland (Tanhuanpää et al., 1999). Only recently, the potential consequences of pupal predation by generalists on the population dynamics of autumnal and winter moths within the outbreak range have also been discussed (Klemola, 2009). The importance of generalist predators for the dynamics of such populations with high-amplitude cycles remains yet to be scrutinised.

Both autumnal and winter moths pupate in the soil, and the majority of their pupal predators are also soil-dwelling invertebrates. Therefore, the limited amount of detailed information on predator responses to prey density that could be gained from laboratory experiments, seemed to be less valuable for elucidating the implications of pupal predation on moth population dynamics, than the information on the total predator response that can be gained from field experiments. Due to the length of cycle 
periods of autumnal and winter moths, studying predation rates at different naturally occurring densities is hardly feasible. In order to get true replicates of the different cycle phases, any experiment would need to be repeated over several complete cycles (i.e. at least 30 years). As the densities of generalist predators are, however, not assumed to follow the moth cycles, the influence of the current cycle phase on the results is likely to be small.

Therefore, in the experiment described in this study, autumnal and winter moth pupae were simultaneously exposed in different densities to the natural predator community, which should allow us to draw conclusions over the whole range of cycle phases. In addition to invertebrate predators, moth pupae are preyed upon also by vertebrates (voles and shrews), but the total number of vertebrate predation events was too low to allow a meaningful analysis of the response of vertebrates to prey density. Thus, only the total response of generalist invertebrate predators to prey density was analysed for both moth species. Furthermore, the influence of pupal mass on the probability of invertebrate predation was analysed as a potential source for differences in predation between winter and autumnal moths.

\section{MATERIALS AND METHODS}

\section{Study species}

Autumnal and winter moths are medium-sized nocturnal moths [wingspan: autumnal moth: $25-35 \mathrm{~mm}$; winter moth (male): $22-28 \mathrm{~mm}$; winter moth females are virtually wingless]. They are obligatorily univoltine, and their eggs overwinter and hatch at host plant budburst. The polyphagous larvae feed on foliage during their five larval instars and pupate in the soil by mid-summer, with autumnal moths preceding winter moths in all stages by approximately a week (Mjaaseth et al., 2005). Owing to the large individual variation in the pupal phase length (Peterson \& Nilssen, 1998; Tammaru et al., 1999), flight periods of populations last at least a month each autumn. Autumnal moths eclose in northern Fennoscandia from early August to late-September, and winter moths from mid-September to mid-October (Peterson \& Nilssen, 1996, 1998; pers. obs. by the authors), with males preceding females by approximately a week. In both species, adults rely solely on larval-derived resources and do not have to feed for either maintenance or reproduction.

All developmental stages of autumnal and winter moths are attacked by various predators such as ants, beetles, spiders, insectivorous birds, and small mammals (voles and shrews) (Tanhuanpää et al., 1999, 2003; Ruohomäki et al., 2000; Tanhuanpää et al., 2001; Enemar et al., 2004; Hogstad, 2005). Furthermore, several parasitoid species are known to attack either the autumnal or the winter moth or both species. 
Different studies have found at least one egg parasitoid, one egg-larval, one larvalpupal, and approximately 15 larval and 5 pupal species (Ruohomäki, 1994; Ruohomäki et al., 2000; Klemola et al., 2007; Klemola, 2009; T. Klemola \& K. Ruohomäki, unpublished).

\section{Study area}

The study was carried out in the immediate vicinity of the Kevo Subarctic Research Station $\left(69^{\circ} 45^{\prime} \mathrm{N}, 2^{\circ} 01^{\prime} \mathrm{E}\right.$; $80 \mathrm{~m}$ a.s.l.) in northernmost Finland in summer 2008. During this year, the natural larval abundance of both moth species was low in the Kevo area (Kai Ruohomäki, pers. comm. and pers. obs. by the authors), as both species were in the bottom phase of their cycles there. Similarly, pupal parasitoids, which follow the densities of the moth populations with a time-lag, were also in the low density phase of their cycle. The pupal exposure experiment was conducted in an unconfined 2.5-ha forest area within a large continuous forest northeast of Lake Kevo. The forest was divided into two adjacent sites by a small (width $3 \mathrm{~m}$ ) gravelled forest road. The whole forest was dominated by mountain birches and Scots pines (Pinus sylvestris L.; Pinales: Pinaceae) with dwarf shrubs, mainly bilberry (Vaccinium myrtillus L.), bog bilberry (V. uliginosum L.), lingonberry (V. vitis-idaea L.), and northern mountain crowberry [Empetrum nigrum L. ssp. hermaphroditum (Lange ex Hagerup) Böcher] (all: Ericales: Ericaceae).

\section{Experimental design}

In each of the two forest sites, 10 square plots of $4 \mathrm{~m}^{2}$ size were established in two parallel transects $(2 \times 5$ plots $)$ with an inter-plot distance of ca $20 \mathrm{~m}$. The location of each plot was marked with coloured paper string at the closest tree and the GPS coordinates were recorded. The 10 plots within each site contained moth pupae of both species in seven different densities, with each of the three lowest densities replicated twice. The different densities were $8,12,18,32,50,72$, and 144 moth pupae per plot, with 50\% autumnal and 50\% winter moths maintained. This corresponds to densities of $2,3,4.5,8,12.5,18$, and 36 pupae per $\mathrm{m}^{2}$. The different densities were randomly assigned to the different square plots. In total, 748 pupae were used for this experiment.

Ten-day-old laboratory-raised and parasitoid-free pupae were sexed and weighed (from 12 to 16 July 2008, depending on availability) and exposure started for all pupae on 17 July 2008. The pupae were buried a few centimetres deep to the moss layer in small cages of green plastic mesh $(6 \times 3 \times 4 \mathrm{~cm}, 0.5 \mathrm{~cm}$ mesh, open top). The cages were filled with moist Sphagnum moss, which is among the natural pupation substrates of both moth species. Each pupa had an individual identification code, which was written onto a label and attached to the bottom of the cage. Each cage contained one 
autumnal and one winter moth pupa, except in the highest density plot, where each cage contained two pupae of each species. In these cages, a dividing wall (of the same plastic mesh as used for the cages) was used in order to allow the re-identification of individuals after the exposure. Thus, each half of the cage contained one autumnal and one winter moth pupa. Doubling the number of moths per cage in the highest density plots was necessary, as 36 cages was the maximum number of cages that could be allocated to $4 \mathrm{~m}^{2}$, while still allowing us to set the cages without stepping onto cages that were already set. The cages were arranged in a grid system within each plot (Fig. 1) and each grid point was marked with a $20 \mathrm{~cm}$ long wooden stick.

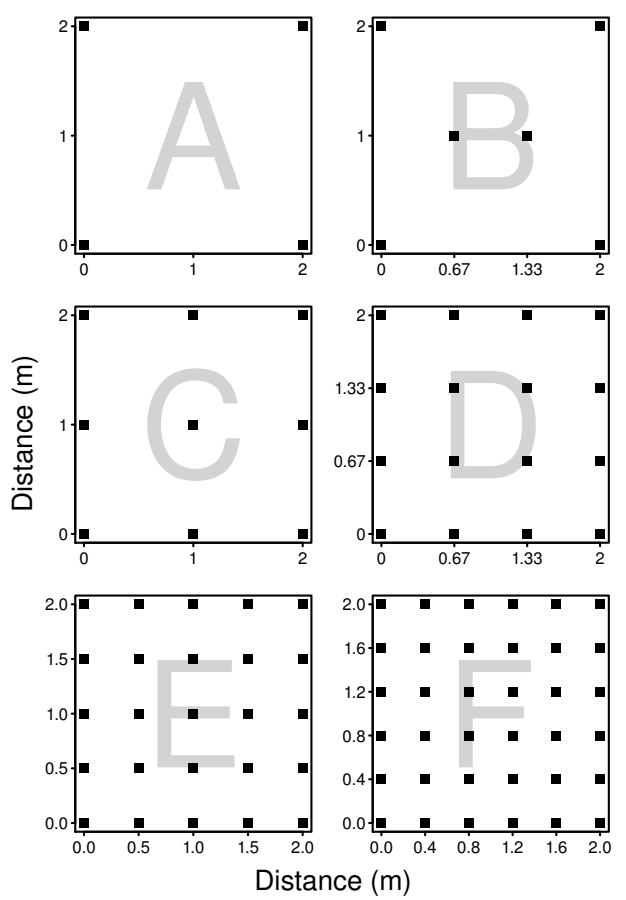

Fig. 1. Spatial arrangement of mesh cages in the study plots with (a) 4, (b), 6, (c) 9, (d) 16, (e) 25, and (f) 36 cages. Each cage contained one autumnal and one winter moth pupa, except in the highest density treatment (g, not shown), where each cage contained two autumnal and two winter moth pupae. The spatial arrangement of cages in the highest density plots was identical to the second-highest density plots (f).

After a 3-week exposure time (which is approximately half of the median natural pupal period), the cages were re-collected on 7 August 2008 and brought to the laboratory to check the fate of the pupae. Invertebrate predation was identified based on specific feeding marks on the pupa (Frank, 1967a,b; Tanhuanpää et al., 1999). Vertebrate predation was assumed to have occurred when the pupa had disappeared totally (Tanhuanpää et al., 1999; Klemola, 2009). Two autumnal moth pupae were dead at the time of re-collection and were thus omitted from the data analyses. Although pupal parasitism was not in the focus of this study, all non-predated pupae were stored in a 
climatic chamber and the fate (successful eclosion or death due to either parasitism or unknown reasons) of each individual was recorded. The majority of all pupae eclosed successfully (172 of 180 winter moths, and 291 of 297 autumnal moths, which corresponds to $96 \%$ and $98 \%$, respectively) and no pupal parasitism events were observed. The remaining eight winter and six autumnal moth pupae died due to unknown reasons. As, first of all, these pupae seemed to be alive at the time of re-collection, and secondly, the removal of these 14 individuals from the analyses did not change the results qualitatively, we decided to keep them in the dataset.

\section{Statistical analysis}

As no detailed information about the composition of the predator community or even single predation events was available, it did not seem reasonable to try to fit mechanistic response models (e.g. specific functional response models like the Holling Disc Equation) to the obtained field data. Instead, three general types of responses (1) linear, (2) asymptotic exponential $[y=a \times(1-\exp (-b x))]$, and (3) sigmoid $y=a /[1+b \times \exp (-c x)]$ were fitted to the data using the 'glm' and 'nls' functions of the statistics software R 2.8.1 (R Development Core Team, 2008) in order to determine the most likely shape of the total predator response to prey density. Akaike's Information Criterion corrected for small sample size (AICc) as well as Akaike's weight $\left(\omega_{i c}\right)$, which was used as model selection criteria (Burnham \& Anderson, 2002) via the 'selMod' function in the R-package 'pgirmess' (Giraudoux, 2008).

Furthermore, the relationship between the proportion of predated pupae and the initial pupal density, which can give further information about the most likely shape of the total predator response to prey density, was estimated by local polynomial regression fitting, using the 'loess' function in R 2.8.1. This visual exploration method was chosen, as the low number of replicates and the high amount of variation in the data did not allow for rigorous statistical testing. In the case of a linear predator response to prey density, the proportion of predated pupae should be approximately constant across pupal density. In the asymptotic exponential case, the proportion of predated pupae should asymptotically decrease with increasing pupal density. When the predator response to pupal density has a sigmoid shape, the proportion of predated pupae should first increase with pupal density and then decrease when pupal density is higher than the inflection point of the sigmoid predator response curve.

Finally, the probability of invertebrate predation depending on moth species and pupal mass was analysed with generalised linear-mixed effects models (the GLIMMIX procedure in SAS 9.1) with a binomial error distribution and a logit link function. In these models, site (i.e. the two parts of the forest), grid, and cage were used as nested 
random effects ('cage' within 'grid' within 'site') to account for the nested structure of the data.

\section{RESULTS}

Model selection criteria suggested in both moth species that an asymptotic exponential response of the invertebrate predator community to increasing pupal density fits the data best (Table 1, Fig. 2a). However, for autumnal moths, the difference in model probability between the linear and the asymptotic exponential model was very small, while for winter moths the asymptotic exponential model had a two times higher probability than the linear model (Table 1). The probability of the sigmoid model was very low in both moth species (Table 1).

Table 1. Information theoretic model selection criteria used to evaluate how well three different types of models (linear, asymptotic exponential, sigmoid) describe the total response of the invertebrate predator community to pupal densities of autumnal and winter moths. $-2 \log$ likelihood, the number of estimable parameters $(K)$, Akaike's Information Criterion corrected for small sample sizes (AICc), the difference in AICc between each model and the best model $(\triangle \mathrm{AICc})$, as well as the model probabilities $\left(\omega_{i c}\right)$ are given. For each species, the model with the highest model probability is printed in bold letters.

\begin{tabular}{llrrrrr}
\hline Species & Model & $-\mathbf{2} \log$ likelihood & $\boldsymbol{K}$ & AICc & $\Delta$ AICc & $\omega_{\text {ic }}$ \\
\hline Autumnal moth & Linear & -45.99 & 3 & 99.47 & 0.13 & 0.44 \\
& Asymptotic exponential & $-\mathbf{4 5 . 9 2}$ & $\mathbf{3}$ & $\mathbf{9 9 . 3 4}$ & $\mathbf{0}$ & $\mathbf{0 . 4 8}$ \\
& Sigmoid & -46.12 & 4 & 102.91 & 3.57 & 0.08 \\
\multirow{3}{*}{ Winter moth } & Linear & -61.19 & 3 & 129.88 & 1.22 & 0.33 \\
& Asymptotic exponential & $-\mathbf{6 0 . 5 8}$ & $\mathbf{3}$ & $\mathbf{1 2 8 . 6 6}$ & $\mathbf{0}$ & $\mathbf{0 . 6 0}$ \\
& Sigmoid & -61.20 & 4 & 133.06 & 4.40 & 0.07 \\
\hline
\end{tabular}

The visual examination of the relationship between the proportion of predated pupae, and the initial pupal density aided by local polynomial regression fitting, supported the notion of an either linear or asymptotic exponential total predator response to autumnal moth pupal density (Fig. 2b). In contrast, for the winter moth the fitted curve rather suggested a sigmoid total predator response, as the proportion of predated pupae first increased at low pupal densities and then decreased again (Fig. 2b).

In total, almost three times as many winter than autumnal moth pupae were predated by invertebrates (183 vs 69 ). Likewise, the probability of invertebrate predation was significantly higher for winter than for autumnal moths across all densities (species: $F_{1,428}=84.50, P<0.0001$; density $\times$ species: $F_{1,427}=0.10, P=0.749$ ). The pupal mass of winter moths ranged from 22.5 to $54.6 \mathrm{mg}$ (mean $\pm 95 \%$ CI: 40.0 $\pm 0.5 \mathrm{mg})$ and autumnal moth pupae weighed between 51.2 and $116.4 \mathrm{mg}(79.2 \pm 1.1$ $\mathrm{mg}$ ). There was a highly significant negative relationship between pupal mass and the 

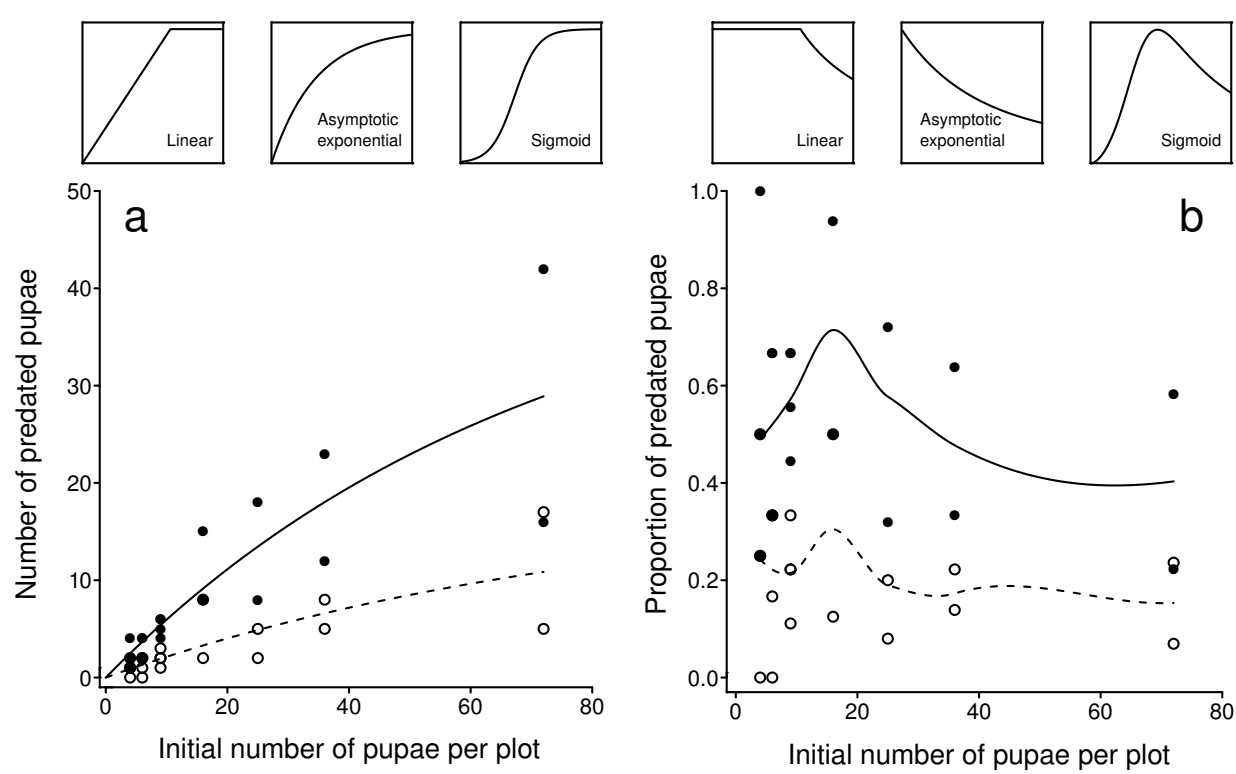

Fig. 2. Total response of the invertebrate predator community to pupal density (a) and relationship between the proportion of predated pupae and pupal density (b). Data and model fits are shown separately for autumnal (open circles, hatched lines) and winter moths (filled circles, solid lines) in both graphs. $n_{1}=4$ plots in the three lowest initial pupal densities (4, 6, 9 pupae of each moth species) and $n_{2}=2$ plots in all other initial pupal densities (16, 25, 36, 72 pupae of each moth species). The shown model fits were obtained by (a) non-linear least-squares regression and (b) local polynomial regression (loess). Above each graph, hypothetical examples of three potential relationships (linear, asymptotic exponential, sigmoid) between total predation and pupal density (a) and the corresponding relationships between the proportion of predated pupae and pupal density (b) are shown.

probability of invertebrate predation for autumnal moths $\left(F_{1,69}=9.34, P=0.0032\right.$; Fig. 3), but not for winter moths $\left(F_{1,68}<0.01, P=0.956\right)$.

\section{Discussion}

Despite substantial research effort, the mechanisms causing cyclic population dynamics in forest pest species are still not thoroughly understood. Even less is known about potential effects of generalist predators that might modify the shape of the cycle during low-density phases. The results of our field experiment on pupal predation suggest an asymptotic exponential response (similar to a type II functional response) of the generalist invertebrate predator community to the density of both winter and autumnal moth pupae in northern Fennoscandia. Overall, winter moth pupae suffered from about threefold higher predation rates by generalist invertebrates than autumnal moths across all tested densities. As a consequence, the influence of invertebrate pupal predation on the population dynamics may be less pronounced in autumnal than in winter moths. This might explain the observed time lag in moth population dynamics, with autumnal 


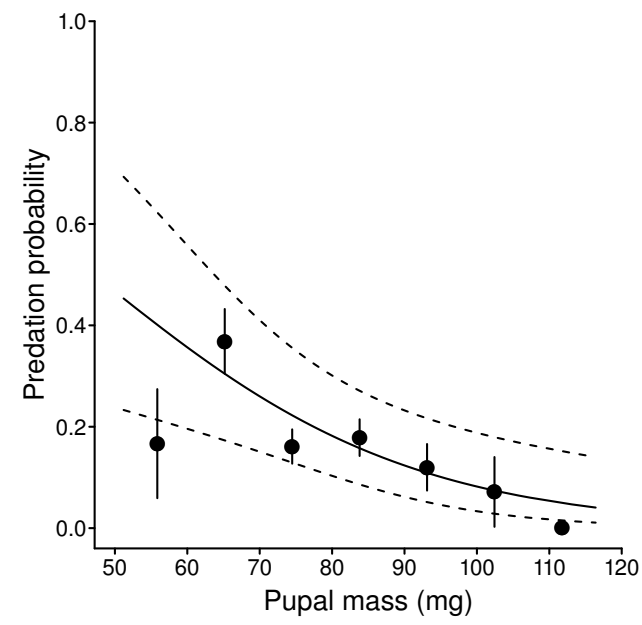

Fig. 3. Probability of invertebrate predation depending on pupal mass for autumnal moths. Plotted are the mean $\pm 1 \mathrm{SE}$ of the incidences of invertebrate predation events in evenly distributed classes of pupal mass and the predicted probability of predation (solid line) with $95 \%$ confidence limits (dashed lines) calculated by the logistic regression model described in the text. $n=366$ autumnal moth pupae. The data are plotted in groups for illustrational purposes only whereas the analyses were performed on the original continuous scale.

moth densities increasing first, followed by winter moths after 1-3 years (Tenow, 1972; Tenow et al., 2007; Klemola et al., 2008; Klemola, 2009).

Model selection criteria suggested an asymptotic exponential response of the invertebrate predator community to increasing pupal densities of both autumnal and winter moths. However, the rather high amount of variation in our dataset made it difficult to decide with high confidence which of the three types of response functions fitted the data best. On the one hand, the model probability of the asymptotic exponential model was almost one order of magnitude higher than the probability of the sigmoid model in the winter moth. On the other hand, however, the relationship between the proportion of predated winter moth pupae and pupal density rather suggested a sigmoid response of the invertebrate predator community. In the autumnal moth, neither model selection criteria nor visual examination of the proportion of predated pupae, depending on pupal density, revealed a clear difference between a linear and an asymptotic exponential response, although the latter had the highest model probability. Furthermore, due to the rather small size of the plots $(2 \mathrm{~m} \times 2 \mathrm{~m})$ in which the experimental densities of pupae were established, edge effects might have obscured any density-dependent responses of predators to pupal density. This is if predators were foraging at the scale of the site rather than the plot, or if predators were aggregating at plots of high pupal density (e.g. Raymond et al., 2002). This might also explain why we did not find such a strongly density-dependent predation as described by Varley et al. (1973) for Wytham Woods and by Roland $(1994,1998)$ in British Columbia. As a consequence, the specific shape of the response of the invertebrate predator community to pupal density cannot fully be 
concluded from the present experimental data. Therefore, implications of the response type for the population dynamics of the two moth species are not further discussed here.

Independent of the exact shape of the response curve, two important things can be concluded from our experiment. Firstly, it can be seen that the invertebrate predator community already starts to get saturated at the pupal densities used in the present study. The highest density of pupae used in our experiment $\left(36\right.$ per $\left.\mathrm{m}^{2}\right)$ was still far below that observed during outbreak phases, when hundreds of pupae per square metre can be found in the forest soil (Frank, 1967a; Varley et al., 1973; Pearsall \& Walde, 1994). This supports previous suggestions that pupal predation is likely to be of little importance in peak and outbreak situations of autumnal and winter moths (Berryman, 1987; Tanhuanpää et al., 2002). In non-outbreaking populations with low-amplitude cycles, pupal predation by invertebrates can, however, have a regulating influence on population density (Tanhuanpää et al., 1999).

Secondly, comparing the response curves for the two moth species, the results of our experiment indicate that the predator community gets saturated at much lower densities of autumnal than of winter moth pupae. As a consequence, autumnal moths seem to be able to escape the regulating influence of their generalist natural enemies at much lower population densities than winter moths. This might affect their population dynamics in the increase phase of the cycle, and could explain why the autumnal moth densities increase first and are followed by the winter moth densities with a 1-3 year time lag. Our results thus support the hypothesis of Klemola (2009) that these diverging population dynamics of autumnal and winter moths in northern Fennoscandia, might, at least partially, be caused by a combined effect of higher larval parasitism rates in autumnal moths in peak and post-peak phases of the population cycles, and higher invertebrate pupal predation rates in winter moths in the low phase of the population cycle.

In order to obtain a more mechanistic understanding of how individual invertebrate predator species react to differences in pupal densities of autumnal and winter moths, and how the predators' responses might affect the population dynamics of the moth species, detailed information about all predator species, their population dynamics, and their foraging behaviour would be required. However, there is only little published information about the composition of the invertebrate predator community in northern Fennoscandia (Koponen \& Ojala, 1975; Koponen, 1984) and also direct observations of pupal predation events are rare. In the literature, mostly larvae but also adults of several beetle species of the families Carabidae, Elateridae, and Staphylinidae have been described as predators of autumnal and winter moth larvae (Frank, 1967b; East, 1974; Roland, 1990; Tanhuanpää et al., 1999; Horgan \& Myers, 2004). Beetle larvae feeding 
on moth pupae were occasionally also encountered in laboratory rearings (pers. obs. by the authors), as the Sphagnum moss that was used as pupation substrate was collected in the forest. Pitfall trapping in the study area during the present experiment remained unsuccessful (data not shown), which suggests that mostly beetle larvae, which cannot usually be caught with pitfall traps (Horgan, 2005), prey upon moth pupae in our study area. More detailed information about the identity of invertebrate predators of autumnal and winter moths in northern Fennoscandia is, however, needed to confirm this assumption.

Even if more detailed information about the predator community had been available, it would have been close to impossible to establish a (laboratory) set-up with an adequate number of replicates of different pupal densities in natural substrate, including controlled numbers of all relevant natural predators. Therefore, a field experiment was the only reasonable way to investigate the total response of the natural predator community to moth pupal density. As a consequence, the resulting data allowed only for a less rigorous way of investigating the potential shape of the predators' response to changes in prey density. Nevertheless, they provide valuable information for estimating the potential impact of pupal predation on the shape of the population cycles of autumnal and winter moths in northern Fennoscandia.

Despite the lack of detailed data on invertebrate predators, it can be assumed that not all invertebrates in the forest soil are able to consume both autumnal and winter moths due to differences in size and texture of the pupal case. In the experiment described here, the pupal mass of winter moths was on average only half that of autumnal moths. The size of the pupa presumably correlates with the thickness and hardiness of the cuticle of the pupal case, which is known to affect food selection of invertebrate predators (Frank, 1967a,b; Roland, 1990). Such a correlation might also be the reason for the negative relationship between the probability of invertebrate predation and pupal mass in autumnal moths (Roland, 1990). The observed differences in the total response of the invertebrate predator community to densities of autumnal and winter moth pupae might therefore be attributable to a combination of several factors: (1) the predator assemblage feeding on the two moth species is most probably not identical; (2) predator species feeding on both moth species might need more time to open the thicker/tougher cuticle of autumnal moth pupae; and (3) autumnal moths - due to their larger size - presumably provide more food per item, thus smaller numbers of them need to be consumed to obtain the same amount of energy compared to winter moths.

As autumnal and winter moth pupae were always exposed in mixed-species assemblages in this experiment, a general preference of invertebrate predators for winter moths could lead to the observed differences in predation rates between autumnal and winter moths, as the latter ones might be eaten preferentially as long as they are avail- 
able. However, similar experiments in the previous season, where pupae of both moth species were exposed to the same predator community but both in single- and in mixedspecies settings, showed the same threefold difference in predation rates irrespective of whether predators could choose between the two species or not (Klemola, 2009). Therefore, it seems unlikely that the lower predation rate in autumnal moth pupae was due to the presence of winter moth pupae.

In our study, less than $3 \%$ of all pupae were predated by vertebrates. This is even less than in previous experiments from the same area [Tanhuanpää et al. (1999) report vertebrate predation rates of 5-35\%] and comparable to our own data from the previous summer, where we found vertebrate predation rates of $<2.5 \%$ in most of the plots (Klemola, 2009). This suggests that pupal predation by vertebrates has probably no major impact on the population dynamics of autumnal and winter moths in northern Fennoscandia. Locally, however, vertebrate predation may have a strong impact on pupal survival, as almost $90 \%$ of pupae were eaten by vertebrates in the previous summer in one plot, which was located in the same forest site where the present experiment was conducted (Klemola, 2009). In total, vertebrate predation seems to be a very stochastic component of pupal mortality in autumnal and winter moth populations.

In summary, our study analysed the response of generalist invertebrate predators to densities of cyclic forest-defoliating Lepidoptera in order to elucidate their potential influence on population dynamics of the pest species. The exact shape of the responses of invertebrates to pupal densities of both moth species could not be finally assessed, due to the high amount of variation in the experimental data. This needs to be studied in more detail in the future. Irrespective of the shape of the response, the saturation point of the response curve was reached at much lower densities for autumnal than for winter moths, which might contribute to the diverging population dynamics of the two moth species in northern Fennoscandia.

\section{ACKNOWLEDGEMENTS}

The authors are grateful to the Kevo Subarctic Research Institute for providing the research facilities as well as to Tommi Andersson, Salla Härkönen, Kati Pihlaja, and Elina Salo for assistance in field and laboratory. Jens Roland provided helpful comments on an earlier draft of this manuscript. The study was financially supported by the Academy of Finland (decision numbers 111195 and 129143 to T.K.), the Maj and Tor Nessling Foundation (grant to T.K., Kari Saikkonen and T.A.), and the Finnish Concordia Fund (grant to N.K.). 


\section{REFERENCES}

Anderson, R. M. \& May, R. M. (1980). Infectious diseases and population cycles of forest insects. Science 210: 658-661.

Berryman, A. A. (1987). The theory and classification of outbreaks. In: Barbosa, P. \& Schultz, J. C. (eds.) Insect Outbreaks, Academic Press, San Diego, pp. 3-29.

Berryman, A. A. (1988). Dynamics of Forest Insect Populations: Patterns, Causes, Implications. Plenum Press, New York.

Berryman, A. A. (1996). What causes population cycles of forest Lepidoptera? Trends in Ecology \& Evolution 11: 28-32.

Burnham, K. P. \& Anderson, D. R. (2002). Model selection and multi-model inference: a practical information-theoretic approach. Springer, New York.

Desurmont, G. A. \& Weston, P. A. (2008). Influence of prey size and environmental factors on predation by Podisus maculiventris (Hemiptera: Pentatomidae) on viburnum leaf beetle (Coleoptera: Chrysomelidae). Canadian Entomologist 140: 192-202.

East, R. (1974). Predation on the soil-dwelling stages of the winter moth at Wytham Woods, Berkshire. Journal of Animal Ecology 43: 611-626.

Enemar, A., Sjöstrand, B., Andersson, G. \& von Proschwitz, T. (2004). The 37-year dynamics of a subalpine passerine bird community, with special emphasis on the influence of environmental temperature and Epirrita autumnata cycles. Ornis Svecica 14: 63-106.

Frank, J. H. (1967a). The effect of pupal predators on a population of winter moth, Operophtera brumata (L.) (Hydriomenidae). Journal of Animal Ecology 36: 611-621.

Frank, J. H. (1967b). The insect predators of the pupal stage of the winter moth, Operophtera brumata (L.) (Lepidoptera: Hydriomenidae). Journal of Animal Ecology 36: 375-389.

Giraudoux, P. (2008). Pgirmess: Data Analysis in Ecology. R package version 1.3.7, URL http:// perso.orange.fr/giraudoux/SiteGiraudoux.html.

Hanski, I., Hansson, L. \& Henttonen, H. (1991). Specialist predators, generalist predators, and the microtine rodent cycle. The Journal of Animal Ecology 60: 353-367.

Haukioja, E., Neuvonen, S., Hanhimäki, S. \& Niemelä, P. (1988). The autumnal moth in Fennoscandia. In: Berryman, A. A. (ed.) Dynamics of Forest Insect Populations: Patterns, Causes, and Implications, Plenum Press, New York, pp. 163-178.

Hogstad, O. (2005). Numerical and functional responses of breeding passerine species to mass occurrence of geometrid caterpillars in a subalpine birch forest: a 30-year study. Ibis 147: 77-91.

Holling, C. S. (1959). The components of predation as revealed by a study of small mammal predation of the European pine sawfly. Canadian Entomologist 91: 292-320.

Holling, C. S. (1965). The functional response of predators to prey density and its role in mimicry and population regulation. Memoirs of the Entomological Society of Canada 45: 1-60.

Horgan, F. G. (2005). Predatory hypogaeic beetles are attracted to buried winter moth (Lepidoptera: Geometridae) pupae: evidence using a new trap design. The Coleopterists Bulletin 59: 41-46.

Horgan, F. G. \& Myers, J. H. (2004). Interactions between predatory ground beetles, the winter moth and an introduced parasitoid on the Lower Mainland of British Columbia. Pedobiologia 48: 23-35.

Ims, R. A., Yoccoz, N. G. \& Hagen, S. B. (2004). Do sub-Arctic winter moth populations in coastal birch forest exhibit spatially synchronous dynamics? Journal of Animal Ecology 73: 1129-1136. 
Jepsen, J. U., Hagen, S. B., Ims, R. A. \& Yoccoz, N. G. (2008). Climate change and outbreaks of the geometrids Operophtera brumata and Epirrita autumnata in subarctic birch forest: evidence of a recent outbreak range expansion. Journal of Animal Ecology 77: 257-264.

Klemola, N. (2009). Trophic interactions and cyclic population dynamics of the autumnal moth: the importance of hymenopteran parasitoids. Ph.D. thesis, University of Turku.

Klemola, T., Andersson, T. \& Ruohomäki, K. (2008). Fecundity of the autumnal moth depends on pooled geometrid abundance without a time lag: implications for cyclic population dynamics. Journal of Animal Ecology 77: 597-604.

Klemola, T., Huitu, O. \& Ruohomäki, K. (2006). Geographically partitioned spatial synchrony among cyclic moth populations. Oikos 114: 349-359.

Klemola, T., Klemola, N., Andersson, T. \& Ruohomäki, K. (2007). Does immune function influence population fluctuations and level of parasitism in the cyclic geometrid moth? Population Ecology 49: $165-178$.

Klemola, T., Tanhuanpää, M., Korpimäki, E. \& Ruohomäki, K. (2002). Specialist and generalist natural enemies as an explanation for geographical gradients in population cycles of northern herbivores. Oikos 99: 83-94.

Koponen, S. (1984). Invertebrates of Inari Lapland, Finland. Kevo Notes.

Koponen, S. \& Ojala, M. L. (1975). Quantitative study of invertebrate groups in the soil and ground layer of the IBP sites at Kevo, northern Finland. Reports from the Kevo Subarctic Research Station 12: 45-52.

Lester, P. J. \& Harmsen, R. (2002). Functional and numerical responses do not always indicate the most effective predator for biological control: an analysis of two predators in a two-prey system. Journal of Applied Ecology 39: 455-468.

Mahdian, K., Vantornhout, I., Tirry, L. \& De Clercq, P. (2008). Effects of temperature on predation by the stinkbugs Picromerus bidens and Podisus maculiventris (Heteroptera: Pentatomidae) on noctuid caterpillars. Bulletin of Entomological Research 96: 489-496.

Mjaaseth, R. R., Hagen, S. B., Yoccoz, N. G. \& Ims, R. A. (2005). Phenology and abundance in relation to climatic variation in a sub-arctic insect herbivore-mountain birch system. Oecologia 145: 53-65.

Myers, J. H. (1988). Can a general hypothesis explain population cycles of forest Lepidoptera? Advances in Ecological Research 18: 179-242.

Pearsall, I. A. \& Walde, S. J. (1994). Parasitism and predation as agents of mortality of winter moth populations in neglected apple orchards in Nova Scotia. Ecological Entomology 19: 190-198.

Peterson, N. A. \& Nilssen, A. C. (1996). Nonlinear temperature-dependent development of autumnal moth pupae, Epirrita autumnata (Lepidoptera: Geometridae). Environmental Entomology 25: 147154.

Peterson, N. A. \& Nilssen, A. C. (1998). Late autumn eclosion in the winter moth Operophtera brumata: compromise of selective forces in life-cycle timing. Ecological Entomology 23: 417-426.

R Development Core Team (2008). R: A language and environment for statistical computing. R Foundation for Statistical Computing, Vienna, Austria, URL http: //www .r-project .org.

Raymond, B., Vanbergen, A., Watt, A., Hartley, S. E., Cory, J. S. \& Hails, R. S. (2002). Escape from pupal predation as a potential cause of outbreaks of the winter moth, Operophtera brumata. Oikos $\mathbf{9 8}$ : 219-228.

Roland, J. (1990). Interaction of parasitism and predation in the decline of winter moth in Canada. In: Watt, A. D., Leather, S., Kidd, N. \& Hunter, M. (eds.) Population Dynamics of Forest Insects, Intercept Publishers, Andover, pp. 289-302. 
Roland, J. (1994). After the decline: What maintains low winter moth density after successful biological control? Journal of Animal Ecology 63: 392-398.

Roland, J. (1998). Population dynamics of Operophtera brumata (Lepidoptera: Geometridae). In: Dempster, J. P. \& McLean, I. F. G. (eds.) Insect Populations: in Theory and in Practice, Chapman \& Hall, London, pp. 289-302.

Ruohomäki, K. (1994). Larval parasitism in outbreaking and non-outbreaking populations of Epirrita autumnata (Lepidoptera, Geometridae). Entomologica Fennica 5: 27-34.

Ruohomäki, K., Tanhuanpää, M., Ayres, M. P., Kaitaniemi, P., Tammaru, T. \& Haukioja, E. (2000). Causes of cyclicity of Epirrita autumnata (Lepidoptera, Geometridae): grandiose theory and tedious practice. Population Ecology 42: 211-223.

Seko, T. \& Miura, K. (2008). Functional response of the lady beetle Harmonia axyridis (Pallas) (Coleoptera: Coccinellidae) on the aphid Myzus persicae (Sulzer) (Homoptera: Aphididae). Applied Entomology and Zoology 43: 341-345.

Sih, A., Englund, G. \& Wooster, D. (1998). Emergent impacts of multiple predators on prey. Trends in Ecology \& Evolution 13: 350-355.

Tammaru, T., Ruohomäki, K. \& Saloniemi, I. (1999). Within-season variability of pupal period in the autumnal moth: a bet-hedging strategy? Ecology 80: 1666-1677.

Tanhuanpää, M., Ruohomäki, K. \& Kaitaniemi, P. (2003). Influence of adult and egg predation on reproductive success of Epirrita autumnata (Lepidoptera: Geometridae). Oikos 102: 263-272.

Tanhuanpää, M., Ruohomäki, K., Kaitaniemi, P. \& Klemola, T. (1999). Different impact of pupal predation on populations of Epirrita autumnata (Lepidoptera; Geometridae) within and outside the outbreak range. Journal of Animal Ecology 68: 562-570.

Tanhuanpää, M., Ruohomäki, K., Turchin, P., Ayres, M. P., Bylund, H., Kaitaniemi, P., Tammaru, T. \& Haukioja, E. (2002). Population cycles of the autumnal moth in Fennoscandia. In: Berryman, A. A. (ed.) Population Cycles: The Case for Trophic Interactions, Oxford University Press, New York, pp. 142-154.

Tanhuanpää, M., Ruohomäki, K. \& Uusipaikka, E. (2001). High larval predation rate in non-outbreaking populations of a geometrid moth. Ecology 82: 281-289.

Tenow, O. (1972). The outbreaks of Oporinia autumnata Bkh. and Operophthera spp. (Lep., Geometridae) in the Scandinavian mountain chain and northern Finland 1862-1968. Zoologiska Bidrag frain Uppsala, Supplement 2: 1-107.

Tenow, O., Nilssen, A. C., Bylund, H. \& Hogstad, O. (2007). Waves and synchrony in Epirrita autumnata / Operophtera brumata outbreaks. I. Lagged synchrony: regionally, locally and among species. Journal of Animal Ecology 76: 258-268.

Turchin, P. (2003). Complex Population Dynamics: A Theoretical/Empirical Synthesis. Princeton University Press, Princeton.

Varley, G. C., Gradwell, G. R. \& Hassell, M. P. (1973). Insect Population Ecology. An Analytical Approach. Blackwell, Oxford.

Accepted 8 July 2009

First published online 14 October 2009 